\title{
Observaciones críticas sobre la Ley n. 3/2019 - Italia (la denominada ley spazzacorrotti)
}

\section{Critical Analysis of the Law 3/2019 (Spazzacorrotti Act)}

\author{
Sheila Jorge Selim de Sales \\ Profesora Titular de Derecho Penal \\ Facultad de Derecho de la Universidade \\ Federal de Minas Gerais - Brasil \\ sheilasales@task.com.br
}

\section{Consideraciones iniciales}

El 16 de enero de 2019, se publicó la Legge 9 gennaio 2019, n. 3, que contiene medidas para contrarrestar la práctica de crímenes contra la administración pública, y disposiciones relativas a la prescripción del delito y a la transparencia de los partidos y movimientos políticos en el Estado italiano. ${ }^{1}$

La nueva ley es también designada en el ambiente político, en los medios de comunicación, y ahora incluso en la doctrina, Legge spazzacorrotti. En su literalidad, la expresión spazzacorrotti significa limpia, barre corruptos. Así, como su nombre indica, su objetivo es contrastar el fenómeno de la corrupción, conteniendo una variedad de medidas penales, muchas de ellas consagrando y concretando el uso meramente simbólico, cada vez más difundida, del derecho penal.

Su aprobación se produjo a pesar de las críticas realizadas por los juristas italianos. Las consideraciones doctrinarias, sin embargo, no surtieron resultados apreciables ni sobre su contenido, ni sobre sus aspectos de redacción, siendo considerada más bien un fruto del "Derecho penal emergencial".

Dicha Ley spazzacorrotti entró en vigor el 31.01.2019, con excepción de las normas relativas a la prescripción contenidas en la misma, que entrarán en vigor el 1 de enero de 2020. La inquietante intervención reformista ha aportado enmiendas no sólo al código penal italiano, sino también al código de procedimiento penal.

En relación con el primero, aumentó la cominación legal en algunos crímenes contra la administración pública, por ejemplo, art. 318 (corrupción para el ejercicio de la función), para el que se preveía la reclusión, de uno a seis años, pasó a ser de tres a ocho años, entre otros. El art. 346, caput fue derogado y el asunto de prohibición contenido en él fue unificado en una sola disposición legal, en el art. 346-bis (tráfico de influencias ilícitas), antes castigado con reclusión, de uno a tres años y actualmente con reclusión, de uno a cuatro años y seis meses.

\footnotetext{
${ }^{1}$ El texto de la ley está disponible en: http://www.giurisprudapenale.com/wpcontent/uploads/\%202019/01/\%20legge-9-gennaio-2019-3.pdf . visitado el 17/05/2019.

${ }^{2}$ MONGILLO (2019), p.231-311.
} 
El reformador también modificó la disciplina de las penas accesorias relativas a la prohibición para el ejercicio de cargos públicos y la incapacidad de establecer contratos con la administración pública. En este último caso, la nueva ley tendría por objeto vetar a los condenados en delitos contra la administración pública, cualquier forma de nuevo acceso y/o contrato con el sector público. Estas penas alcanzan su mayor rigor con la previsión de su perpetuidad en los casos de condena superior a dos años.

La ratio de la prohibición contenida en la reforma sería la comprensión de que, en la práctica, el mero endurecimiento de las penas principales previstas en el código penal italiano no estaría dando resultados significativos en el contraste con la corrupción. ${ }^{3}$

Los delitos de malversación, conmoción cerebral, corrupción, entre otros, son obstáculos para el disfrute de diversos beneficios previstos en la Ordenación Penitenciaria italiana, a menos que el condenado haya colaborado, o aún esté en condiciones de colaborar con la justicia, según el art. 323-bis, del código penal italiano, que prevé una causa especial de reducción de pena introducida por la 1 . 69/2015 para el colaborador en los crímenes contra la administración pública, que no se confunde, por lo tanto, con la causa de no punibilidad inserta por la Ley spazzacorrotti en el art. 323-ter, que se tratará en el punto 2.2, a continuación.

En efecto, en este breve esbozo general, causa perplejidad el fervor represivo del legislador italiano en materia penal para el enfrentamiento a la corrupción.

\section{Algunas modificaciones realizadas por la Ley}

\subsection{Prescripción}

En cuanto a la prescripción, el texto legal trajo modificaciones, que se han convertido en uno de los temas más controvertidos y debatidos de la Legge spazzacorroti. La prescripción, en el Derecho penal italiano, como en el Derecho penal brasileño, es causa de extinción de la punibilidad prevista en el art. 157 y siguientes del código penal peninsular.

El primer cambio realizado sobre el asunto se refiere al caput del art. 158 del c. p. italiano, sustituido por la siguiente disposición: "El término de la prescripción se deriva, para el delito consumado, del día de la consumación; para el delito tentado, del día en que cesa la actividad del culpable; para el delito permanente o continuado, del día en que cesó la permanencia o la continuación". 4

La principal crítica que se puede realizar es concerniente a los aspectos de redacción de la prescripción del delito tentado, al utilizar la expresión "de la actividad del culpable", que se dirige al intérprete para el derecho penal del autor. Mejor si se utilizase la expresión, "terminado el último acto idóneo", el contenido art. 56, c. p. italiano, que prevé la tentativa.

\footnotetext{
${ }^{3}$ Entre las escasas publicaciones sobre el tema, mencione, OREFICE (2019), p. 13-22.

4 In verbis: "Il termine della prescrizione decorre, per il reato consumato, dal giorno della consumazione; per il reato tentato, dal giorno in cui è cessata l'attività colpevole; per il reato permanente o continuato, dal giorno in cui è cessata la permanenza o la continuazione”.
} 
Pero lo que suscita mayor perplejidad es la equiparación realizada con fines de prescripción, entre los institutos de la continuación y de la permanencia. El antiguo texto del art. 158 se refería sólo a la determinación del tiempo necesario para la prescripción del crimen permanente, sin mencionar el crimen continuado.

Se conoce la diferencia entre los dos institutos - permanencia y continuación. "El reformador" italiano en su lugar equiparó con fines de prescripción, permanencia y continuación delictuosa.

El art. 159, que trata de la suspensión de la corrupción, ha sufrido la reformulación más significativa. El comma 2 de la disposición legal mencionada se sustituye por el texto siguiente: "El curso de la prescripción queda suspendido a partir de la pronunciación de la sentencia de primer grado, o del decreto de condena, hasta la fecha de la ejecutividad de la sentencia que define el juicio o la irrevocabilidad del decreto penal de condena". 5

La disposición legal sometida a examen es una norma excéntrica e inusual para no usar términos más fuertes. En caso de que se aplique, en lugar de imprimir velocidad al proceso penal lo estancará.

Vale decir, la modificación suspende el curso de la prescripción de la fecha de pronunciamiento de la sentencia de primer grado, sin hacer distinción entre las dos tipologías posibles de sentencia de primer grado (condenatoria o absolutoria) o hasta la fecha de la sentencia que define el juicio o la fecha de irrevocabilidad del decreto penal de condena.

La norma equipara las dos tipologías de sentencia y, al hacerlo, perjudica al acusado absuelto al final del proceso de primer grado, en la hipótesis en que el ministerio público interponga recurso. La prescripción quedará suspendida para el absuelto, como si hubiera sido condenado, durante todo el período del juicio de apelación, es decir, por un período de tiempo indeterminado.

La modificación introducida está también en claro contraste con el principio de presunción de inocencia, previsto en el artículo. 27, comma 2, de la Constitución italiana. Seguramente en poco tiempo será declarado constitucionalmente ilegítimo. A propósito, ya se ha observado que autorizada doctrina comprende "la suspensión de la prescripción generó una polémica comparada a una especie de ergastolo processuale, en el sentido de que el legislador creó un proceso penal sine die, que corre el riesgo de convertirse en una especie de pena insostenible para todos los participantes - tanto para el imputado, como para la víctima y familiares exactamente porque el proceso puede no terminar jamás". 6

Cabe señalar una vez más que las normas relativas a la prescripción entrarán en vigor solamente en el 1 de enero de 2020.

\footnotetext{
${ }^{5}$ In verbis:"Il corso della prescrizione rimane altresì sospeso dalla pronunzia della sentenza di primo grado o dal decreto di condanna fino alla data di esecutività della sentenza che definisce il giudizio o dell'irrevocabilità del decreto penale di condanna."

${ }^{6}$ PICCIOTTO (2019), p. 18.
} 


\subsection{Causa de no punibilidad: colaboración con la justicia}

Junto a la causa de reducción de pena para la colaboración prevista en el art. 323-bis, del código penal italiano, la ley Legge spazzacorrotti introdujo una causa de no punibilidad, injertando el art. 323-ter, en el código penal. Su ratio sería contrastar la cifra negra de crímenes de corrupción, incrementando la aparición de los hechos de corrupción. $^{7}$

La solución tendría una importancia preventiva general y especial, como también en la relación de solidaridad que une a los contrayentes del acuerdo de corrupción se manifiesta en la introducción de una medida que rompe el vínculo de confianza, el interés mutuo, la seguridad y la ventaja recíproca entre funcionarios públicos y extraneus, que se unen para la comisión del delito.

Basada en el arrepentimiento eficaz, ${ }^{8}$ es impune aquel que colabore con la justicia. Se trata de la autodenuncia.

La no punibilidad está sujeta a dos condiciones:

a) Deberá tratarse de una confesión voluntaria, y tener lugar antes que el interesado tenga noticias de una investigación o procedimiento en su nombre, proporcionando indicaciones útiles y concretas para garantizar la prueba del delito e identificar a otros responsables; y

b) ser realizada hasta cuatro meses después de la comisión del delito. ${ }^{9}$

La causa de no punibilidad no se aplica cuando la colaboración voluntaria es preordenada o premeditada en relación con la comisión del delito, con vistas a la ratio de la disposición, relativa "a la preocupación - expresada todavía en la fase de examen del proyecto de ley - de un uso instrumental del instituto para hacer volver por la ventana la figura del agente provocador, expulsa por la puerta principal". ${ }^{10}$

Sin duda, la no punibilidad es un gran premio al colaborador, pero el texto legal impone, por otra parte, requisitos más sólidos para su concesión: además de la autodenuncia, se requiere la voluntaria, ayuda oportuna y fructífera y cooperación para resolver los crímenes de corrupción.

Finalmente, hay que señalar que la causa especial de no punibilidad se aplica tan sólo al elenco de crímenes establecido en la disposición legal, a saber: corrupción impropia (art. 318), corrupción propia (art. 319), corrupción en actos judiciales (art. 319 ter),

${ }^{7}$ CANTONE y MILONE (2019), p. 10.

${ }^{8}$ Confróntese, PADOVANI (2019) p. 6.

${ }^{9}$ In verbis: "Art. 323-ter (causa de non punibilità) - Non è punibile chi ha commesso taluno dei fatti previsti dagli articoli 318, 319, 319-ter, 319-quarter, 320, 321,322-bis, limitatamente ai delitti di corruzione e di induzine indébita ivi indicati, 353 , 353-bis e 354 se, prima di avere notizia che nei suoi confronti sono svolte indagini in relazione a tali fatti e, comunque, entro quattro mesi dalla comissione del fatto, lo denuncia volontariamente e fornisce indicazioni utili e concrete per assicurare la prova del reato e per individuare gli altri responsabili.

${ }^{10}$ CANTONE y MILONE (2019), p. 19. 
inducción indebida a dar o prometer utilidad (art. 319-Quarter), corrupción activa (art. 321), todos ellos del código penal italiano, entre otros delitos contra la administración pública.

Se acentúa solamente que medidas utilitarias como esta ven multiplicándose en el derecho penal, en una atmósfera progresiva de premios y recompensas.

\section{Consideraciones finales}

Estas son sólo algunas observaciones relativas a las dos instituciones tratadas.

La denominada Legge spazzacorrotti ha introducido una reforma mucho más amplia en el sistema penal italiano, que la mera modificación o introducción de los dos institutos, esbozada aquí.

Sin duda es una ley utilitaria, excesivamente simbólica, y que será muy combatida por los penalistas italianos para ofrecer soluciones alternativas de interpretación, e indicar las inconstitucionalidades contenidas en ella.

Hasta el momento en que se escribían estas notas, no encontramos una bibliografía consistente sobre la cual pudiéramos efectuar una crítica más concreta.

Por lo demás, nos encontramos ante un excelente texto de Manes, que no se refiere a los temas aquí tratados, pero que, al hablar de la Ley spazzacorrotti, dice: con ella se introducen novedades en abundancia, todas capaces de alterar profundamente un sector ya perjudicado por reformas compulsivas, dictadas por el ritmo incesante de una perdurante emergencia, y unívocamente inspiradas en el endurecimiento del instrumento represivo, según un trend seguro y no limitado a la progresiva escalation de las penas editales. ${ }^{11}$

Pero, evidentemente, es la costumbre demostrar las inconsistencias y la eficacia de las medidas impuestas por la ley promulgada.

En resumidas cuentas, estas son las innovaciones más importantes introducidas por la denominada Legge spazzacorrotti en Italia.

\footnotetext{
${ }^{11}$ MANES (2019), p. 105, In verbis: "Con essa vengono introdotte novità a profusione, tutte capaci di alterare profondamente un settore già vessato da riforme compulsive, incalzate dal ritmo incessante di una perdurante emergenza, e univocamente ispirate all'irrigidimento dello strumentario repressivo, secondo un trend certo non limitato alla progressiva escalation delle cornici edittali."
} 


\section{Bibliografía citada}

CANTONE, Raffaele; MILONE, Alessandro (2019): "Prime riflessioni sulla nuova causa di non punibilità di cui all'art. 323-ter c. p.", en: Diritto penale cont., (n. 6/2019), pp. 5-21.

MANES, Vittorio (2019): "L'estensione dell'art. 4-bis ord. Pen. ai delitti contro la P. A.: profili di illegittimità costituzionale", en: Diritto penale cont., (n. 2/2019), pp. $105-138$.

MONGILLO, Vincenzo (2019): La legge spazzacorrotti: ultimo approdo del diritto penale emergenziale nel cantiere permanente dell'anticorruzione. In: Diritto penale cont., (3/2019), p.231-311.

OREFICE, Martina (2019): "Delle pene acessorie in particolare", en: org. CONZ, Andrea; LEVITA, Luigi, La nuova legge anticorruzione (Roma, Dike).

PADOVANI, Tullio (2018): La spazzacorrotti. Riforma delle illusioni e illusioni della reforma. Disponible en: http://www.archiviopenale.it/File/DownloadArticolo?codice=481dee02-bc7847f3-979a-a29a1dcd6612\&idarticolo=18518 [visitado el 25/05/2019]

PICCIOTTO, Guido (2019): La legge spazzacorrotti (Napoli, Simone). 